\title{
TURBULENT HEAT TRANSFER FOR INTERNAL FLOW OF ETHYLENE GLYCOL- AL2O3 NANOFLUID IN A SPIRAL GROOVED TUBE WITH TWISTED TAPE INSERTS
}

\author{
Ahmed Fakhrey Khudheyer ${ }^{1 *}$, Audai Hussein Al-Abbas² ${ }^{2}$ Mihail-Bogdan Carutasiu ${ }^{3}$, Horia Necula $^{3}$
}

\begin{abstract}
Numerical investigation for turbulent flow of nanofluid (Ethylene glycol/water-Al2O3) is carried out with a volume fraction of $0.5 \%, 1 \%$, and $1.5 \%$. The diameter of solid nanoparticles is equal to $20 \mathrm{~nm}$. The range of Reynolds number in this simulation is from 6300 to 27500 through a three-dimensional steel corrugated spirally tube. For enhancement of the heat transfer performance in internal flow through the horizontal tube, the tube is combined with aluminum twist tape of a thickness of $0.8 \mathrm{~mm}$ and a width of $10 \mathrm{~mm}$ along the spirally corrugated tube. In the present work, the same twisted ratios $\mathrm{TR}=(\mathrm{y} / \mathrm{w})$ are implemented for corrugated tube and tape. The predicted results showed that there is a clear increase in the values of heat transfer and the pressure drop in the direction of flow. Furthermore, the friction factor is increased because of the grooved and twisted tape which rise the resistance of the fluid flow. The values of Nusselt number are increased with the VOF of nanofluid. These numerical results are compared with the experiment found in the literature and showed a good agreement.
\end{abstract}

Keywords: Ethylene glycol, Water-A/2O3, Numerical analysis, Corrugated spirally tube, Heat transfer, Internal flow.

\section{INTRODUCTION}

The nanofluid technique has recently been considered an effective technique for the high enhancement of cooling/heating systems in many industrial applications. The nanofluid particles can efficiently increase the thermal conductivity and specific heat capacity of the working fluid, and lead as a result improved heat transfer performance [1]. In addition to that, inserting a twisted tape, which increases the turbulent intensity, significantly increases the heat transfer as well. The twisted tape (TT) creates a fluid flow swirl; this swirling effect makes a turbulent flow that improves the heat transfer performance. However, this fluid flow swirl might lead to an increase in the friction factor value in the tube.

In the case of the cooling liquid system, one of the most leading parameters, which is used to estimate the heat variation is the thermal conductivity. Cong Qi, et. al. [2] found that when adding $0.3 \%$ nanoparticles of cupper to ethylene glycol (EG), the thermal conductivity of this nanofluid increased by $40 \%$. This increases in thermal conductivity was also found in other studies with different concentrations of nanofluid particles [3]. Furthermore, using twisted tape in a spirally corrugated tube can improve the heating effectiveness. However, these enhancements in the heat transfer characteristics are inadequately connected with the increase in the friction factor in the inner surface of the tube [4], [5] deal with The effect of wall corrugation on the convective heat transfer in coiled tubes was investigated. Both were characterized by eight coils with a diameter of helix and a pitch of $310 \mathrm{~mm}$ and $200 \mathrm{~mm}$ respectively, resulting in a coiled pipe length of about $10 \mathrm{~m} \mathrm{~L}$. The corrugated-wall tube is included in the general category, usually known as spirally enhanced tubes. For the investigated fluid velocity ranges, the heat flux provided to the fluid was selected to make the buoyancy forces negligible compared to the inertial forces. In the corrugated surface there is more pressure drop compared to the smooth pipe, but the heat transfer rate increases as the surface area increases in the case of corrugations. Experimental analysis utilized numerical simulations to investigate the effect of spiral corrugation in a simple tube on the heat transfer and friction factor. In comparison to the smooth pipe, the pressure falls at the corrugated surface, but the rate of heat transfer increases as the surface area increases with corrugations. Experimental analysis examined with numerical simulations the effect of spiral corrugation in a simple tube on thermal transfer and friction. The behavior of both fluid and spirally corrugated tubes, with turbulent flows at 4 Reynolds 15000-40000 and 2 Prandetl (2.9 and 4.3) numbers. Stainless steel tubes with an internal diameter of $18 \mathrm{~mm}$, a length of $6 \mathrm{~m}$ and a wall thickness of $1 \mathrm{~mm}$ have been used for smooth and on-board tubes. The corrugated tube was $0.43 \mathrm{~mm}$ deep and 15.86

This paper was recommended for publication in revised form by Regional Editor Nader Javani.

${ }^{1}$ Department of Mechanical Engineering, Al-Nahrain University, Baghdad, IRAQ

${ }^{2}$ Pumps Engineering Department, Technical College of Al-Musaib, Al-Furat Al-Awsat Technical University, Kufa, IRAQ

${ }^{3}$ University Politehnica of Bucharest, Faculty of Power Engineering, Bucharest, Romania.

${ }^{\star}$ E-mail address: drahmed955@eng.nahrainuniv.edu.iq

Orcid ID: 0000-0003-1965-1412, 0000-0002-5809-4105, 0000-0002-4352-4299, 0000-0002-5809-4105.

Manuscript Received 28 March 2020, Accepted 16 June 2020 
$\mathrm{mm}$ helical pitch. The results show that the number model for the corrugated tube predicts an average Nusselt number of up to 17 percent relative error compared to the experimental data and the Fanning factor differences of less than 9 percent. Stainless steel tubes with an internal diameter of $18 \mathrm{~mm}$ and a wall thickness of $1 \mathrm{~mm}$ were applied to smooth and corrugated tubes. The highest fanning friction values for the on-tube were obtained, with differences between the on-tube and smooth tubes observed. These differences were approximately $86 \%$ (Reynolds $15^{*} 10^{3}$ ) and $100 \%$ higher for the corrugated tube (Reynolds $40^{*} 10^{3}$ ) than for the smooth [6],[7]. In the present study, the heat transfer characteristics and friction factor were numerically investigated for turbulent internal flow. The spirally corrugated tube with twisted taped was used with TR of 2 and 5, and volume of fraction $0.5 \%, 1 \%$, and $1.5 \%$. The boundary conditions, specifications, and operating parameters are set up based on the experiments found in the literature by Ref.[1]. The temperature distributions and pressure drop were investigated and presented. The predicted results were compared with the experimental data and showed good agreement.

\section{MODELING AND SIMULATION}

The present investigation deals with the forced convection heat transfer and turbulent nanofluid flow in a stainless steel pipe with an internal spiral corrugated pipe, the semicircular pipe of diameter (D) is $0.015 \mathrm{~m}$, and the length (L) is $0.8 \mathrm{~m}$. The pipe is made from aluminum with twist tape, and has a thickness of $0.8 \mathrm{~mm}$ and a width of $10 \mathrm{~mm}$ along the spirally corrugated tube with the same twisted ratio of the pipe [1], as shown in Fig.1. The tube was heated on a circumferential surface with a constant heat flux.
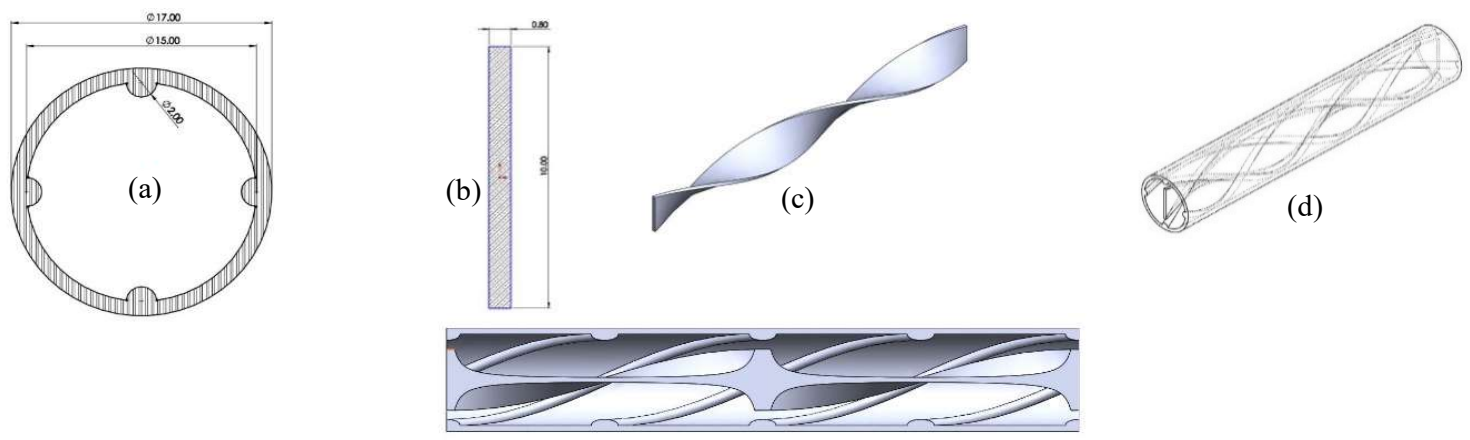

(e)

Figure1. Configuration used in the present study (all dimensions in $\mathrm{mm}$ ): (a) corrugated tube cross sectional, (b) TT cross sectional, (c) TT, (d) circular tube with spiral grooved and TT, and (e) cross section for the system.

The nanofluid contained two parts. The first is the base fluid of (EG-water), and the second is A12O3 nanoparticles. It is appropriate to find the properties of the base fluid at $300 \mathrm{~K}$.

Thermal properties for water, Ethylene glycol (EG) and Al2O3 are summarized in Table 1 [8].

Table 1. Thermophysical properties at $\mathrm{T}=300 \mathrm{~K}$

\begin{tabular}{llll}
\hline Property & Water & EG & A12O3 \\
\hline$\rho\left(\mathrm{kg} / \mathrm{m}^{3}\right)$ & 998.9 & 1114.4 & 3597 \\
$\mathrm{k}(\mathrm{W} / \mathrm{m} . \mathrm{K})$ & 0.6352 & 0.2491 & 34.8 \\
$\mathrm{Cp}(\mathrm{J} / \mathrm{kg} \cdot \mathrm{K})$ & 4188.3 & 2409.8 & 764.7 \\
$\mu\left(\mathrm{kg} \cdot \mathrm{m}^{-1} \cdot \mathrm{s}^{-1}\right)$ & 0.0008755 & 0.01566 & -
\end{tabular}


The following required equations [9] are arranged as shown below:

$$
\begin{gathered}
\rho_{b f}=1090.6-0.32857 T-0.00286 T^{2}+5.421 * 10^{-19} T^{3} \\
C_{p b f}=3044.135+0.00111 T-0.00186 T^{2}+1.55759 * 10^{-5} T^{3} \\
k_{b f}=0.33944+0.00111 T-0.0000100528 T^{2}+0.0000000377393 T^{3} \\
\mu_{b f}=0.0087-0.000245439 T+0.00000282043 T^{2}-0.00000001178 T^{3}
\end{gathered}
$$

The properties of nanofluid are determined by using the following equations, and the conditions for the using correlations are in the ranges of, $(0 \leq \varphi \leq 4 \%),\left(20 \leq T_{n f} \leq 90^{\circ} \mathrm{C}\right)$ and $\left(20 \leq d_{p} \leq 50 \mathrm{~nm}\right)[8,10]$.

$$
\begin{gathered}
\rho_{n f}=\left(\varphi_{p} / 100\right) \rho_{p}+\left(1-\varphi_{p} / 100\right) \rho_{b f} \\
C_{p n f}=\frac{\left[\left(1-\frac{\varphi_{p}}{100}\right)\left(\rho C_{p}\right)_{p}\right]}{\rho_{n f}} \\
\mu_{n f}=\mu_{b f} * 1.07\left(1+\frac{\varphi}{100}\right)^{17.69}\left(1+T_{n f} / 90\right)^{-0.06726}\left(1+d_{p} / 53\right)^{-0.1178} \\
k_{n f}=k_{b f} * 0.852(1+\varphi / 100)^{2.608}\left(1+T_{n f} / 97\right)^{0.003889}(1 \\
\left.+d_{p} / 77\right)^{-0.08427}\left(\alpha_{p} / \alpha_{b f}\right)^{0.04192}
\end{gathered}
$$

\section{Governing Equations}

A steady-state and turbulent flow in a three-dimensional modeling investigation is implemented in this study. The nanofluid thermophysical properties are assumed to be variable with temperature. For the turbulent modeling, the popular turbulent flow model of $(\kappa-\omega-\mathrm{SST})$ is used. The governing equations for the present problem can be shown as follows [11]:

- Continuity equation:

$$
\frac{\partial}{\partial X_{i}}\left(\rho u_{i}\right)=0
$$

- Momentum equations:

$$
\frac{\partial}{\partial X_{j}}\left(\rho u_{i} u_{j}\right)=-\frac{\partial P}{\partial X_{i}}+\frac{\partial}{\partial X_{j}}\left[\mu\left(\frac{\partial u_{i}}{\partial X_{j}}+\frac{\partial u_{j}}{\partial X_{i}}-\frac{2}{3} \delta_{i j} \frac{\partial u_{i}}{\partial X_{j}}\right)\right]+\frac{\partial}{\partial X_{j}}\left(-\rho \overline{\widetilde{u_{\imath}} \widetilde{u_{j}}}\right)
$$

- Energy equation:

$$
\frac{\partial}{\partial X_{i}}\left(u_{i}(E \rho+P)\right)=\frac{\partial}{\partial X_{j}}\left[\left(\lambda+\frac{C_{p} \mu_{t}}{P r_{t}}\right) \frac{\partial T}{\partial X_{j}}+u_{i}\left(\tau_{i j}\right)_{e f f}\right]
$$


Where $\left(\tau_{i j}\right)$ is the stress tensor,

$$
\left(\tau_{i j}\right)_{e f f}=\left(\mu_{e f f}\left(\frac{\partial u_{i}}{\partial X_{j}}+\frac{\partial u_{j}}{\partial X_{i}}\right)-\frac{2}{3} \delta_{i j} \frac{\partial u_{i}}{\partial X_{j}} \mu_{e f f}\right)
$$

And total energy,

$$
\begin{gathered}
E=C_{p} T-(P / \rho)+\left(u^{2} / 2\right) \\
\frac{\partial}{\partial X_{i}}\left(\rho k u_{i}\right)=\frac{\partial}{\partial X_{j}}\left(\Gamma_{k} \frac{\partial k}{\partial X_{j}}\right)+\widetilde{G_{k}}-Y_{k}+S_{k} \\
\frac{\partial}{\partial X_{i}}\left(\rho \omega k u_{i}\right)=\frac{\partial}{\partial X_{j}}\left(\Gamma_{\omega} \frac{\partial \omega}{\partial X_{j}}\right)+G_{\omega}-Y_{\omega}+D_{\omega+} S_{\omega}
\end{gathered}
$$

Where $G_{k}$ is the kinetic energy of the turbulence generator because of the velocity gradient, and $G_{\omega}$ is the source term:

$$
\begin{gathered}
\widetilde{G_{k}}=\min \left(G_{k}, 10 \beta^{*} k \omega\right) \\
G_{k}=-\overline{\widetilde{\rho u_{\imath}} \widetilde{u}_{\jmath}}\left(\frac{\partial u_{j}}{\partial X_{i}}\right) \\
G_{\omega}=\frac{\alpha}{v_{t}} G_{k} \\
\alpha=\alpha_{\infty} \frac{\left(\alpha_{0}^{*}+R e_{t} / 2.95\right)}{\left(1+R e_{t} / 2.95\right)}
\end{gathered}
$$

\section{Boundary Conditions}

The three-dimensional turbulent flow is investigated numerically in the present study for nanofluid flows through a spirally corrugated tube with a twisted tape inserted. The steady-state condition with a heat flux of 5000 $\mathrm{W} / \mathrm{m} 2$ was applied on the external surface of the pipe. As shown in Figure 2, the working fluid enters with uniform velocity and temperature of $300 \mathrm{~K}$. Walls of the spirally corrugated tube and twisted tape are no-slip boundary condition. The spiral corrugated tube was made of steel, and the twisted tape material was aluminum. For the current study, a numerical simulation was carried out for the nanofluid (EG/water-Al2O3) with concentrations of $0.5 \%, 1 \%$, and $1.5 \%$. The size of the nanoparticles used in the present study was $20 \mathrm{~nm}$. A uniform velocity entered the inlet section, where the mixture was considered as a single-phase fluid flow. The nanofluid properties are used as a function of the bulk temperature, as shown in equations. The shear stress transport (k- $\omega$-SST) model was used for the turbulent flow effect. 


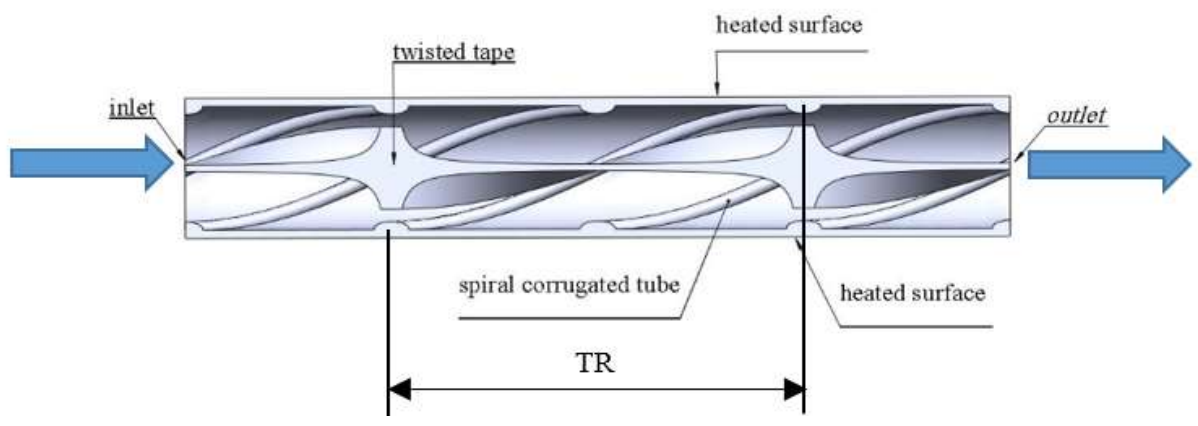

Figure 2. Boundary conditions

\section{Numerical Method and Validation}

The FVM is used to solve the governing equations after the modeling process. This was numerically done by ANSYS FLUENT2019R1 for the computational fluid domain. The upwind scheme was used to discretize the convective and viscous for more accuracy. The convergence was taken less than 10-15 for all equations. The meshing process was accomplished using the tetrahedral element type. The simulation was carried out with ten cases of grid number by changing the element size. Table 2 shows the independence test for the calculated outlet temperature of the tube. According to the result of this grid test, the mesh chosen is 20311758 elements with an average number of discretization points. The tetrahedral element type was used as the finest $3 \mathrm{D}$ mesh for the present study, as shown in Figure3.

Table 2. Mesh independence, with $\mathrm{Re}=7250$

\begin{tabular}{|c|c|c|c|c|c|c|c|c|c|c|}
\hline $\begin{array}{l}\text { Mesh } \\
\text { No. }\end{array}$ & 4007532 & 5610462 & 6665988 & 8879253 & 14432978 & 16398124 & 17440559 & 20311758 & 29046298 & $1.49 \mathrm{E}+08$ \\
\hline$T_{\text {out }}(K)$ & 304.1 & 308 & 311.2 & 319.4 & 342.1 & 350.3 & 365.7 & 373 & 373.05 & 373.1 \\
\hline
\end{tabular}

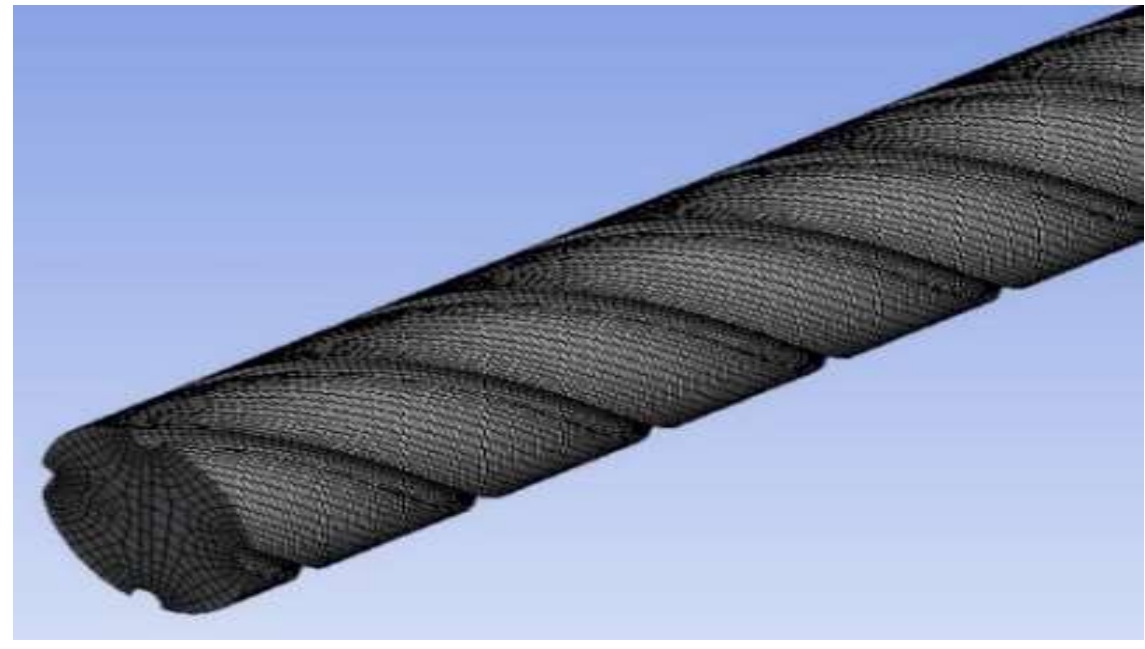

Figure 3. 3D Meshing model of fluid domain

\section{Validation}

To ensure the reliability of these predicted results, they were compared with the measured data found in the literature [1]. For the same boundary conditions of fluid flow properties and heat transfer characteristics, the effects of the internal tube surface smooth and/or spirally corrugated with or without twist tape (TT) are carried out. The values of friction factor and $\mathrm{Nu}$ for the plain horizontal tube are validated with the values of Re between the numerical results and experiments [1], as shown in Figure 4b and Figure 5a. For the Dittus-Boelter correlation, 
Journal of Thermal Engineering, Technical Note, Vol. 7, No. 4, pp. 761-772, May, 2021

$$
N u=0.023 \operatorname{Re}^{0.8} \cdot \operatorname{Pr}^{0.4}
$$

These validations were for heat transfer and fluid flow characteristics, which are represented by values of the friction factor, and based on the Blasius equation[12],

$$
f=0.31 R e^{-0.25}
$$

Where, $R e=\frac{4 \dot{m}}{\pi d \mu}, \dot{m}$ is the mass flow rate $[\mathrm{kg} / \mathrm{s}], \mathrm{d}$ is the hydraulic diameter of the pipe.

It is clear that from Figs.4b and 5a, the behavior of the numerical, experimental, and Dittus and Bolter correlation for the Nusselt number is approximately the same, but there is a deviation of the numerical results compared that for an experiment about $2.05 \%$. For the friction factor, the agreement was good, and the deviation was less which is approximately $0.04 \%$.
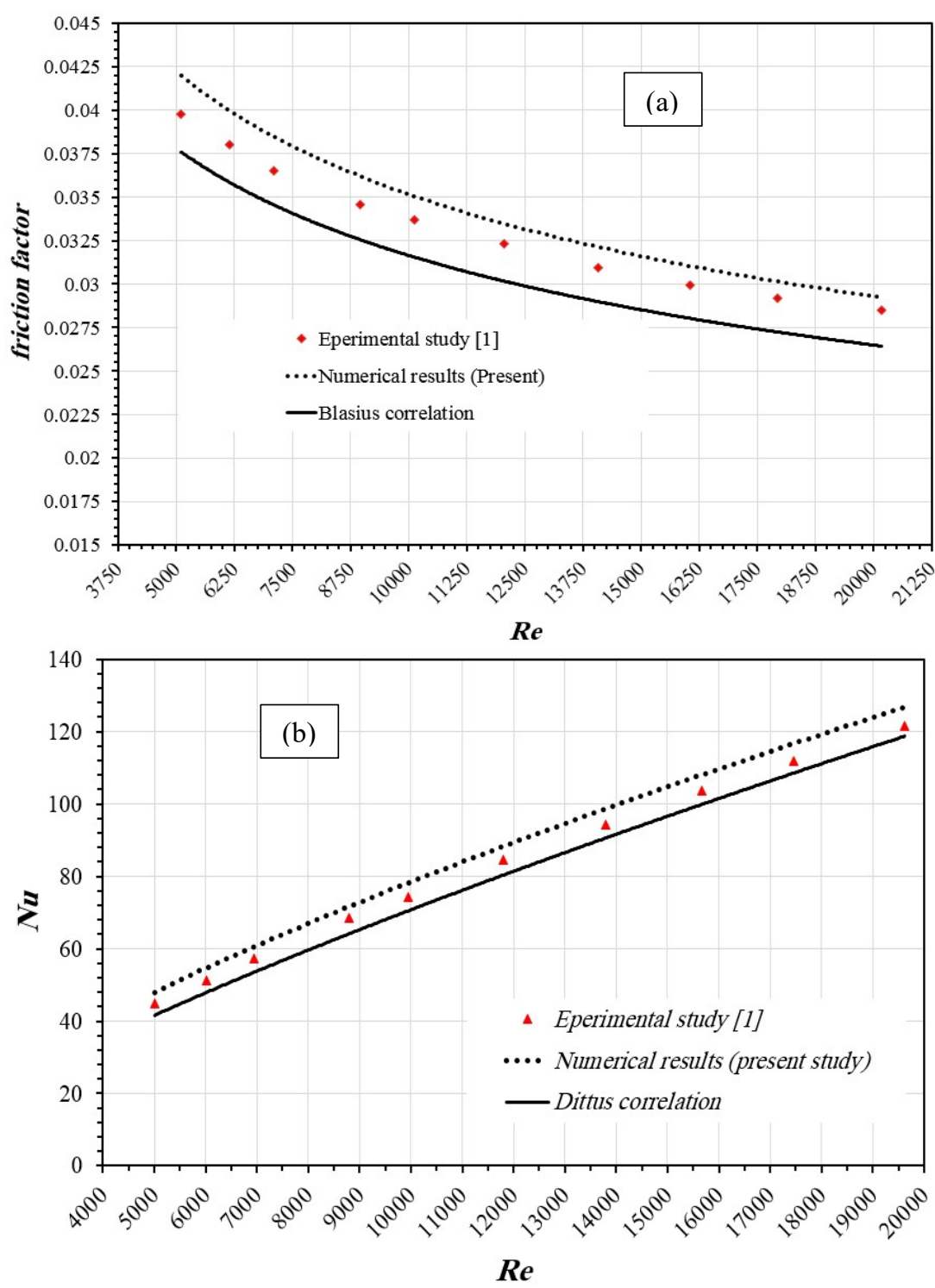

Figure 4. For plain horizontal tube: (a) variation of friction factor with Reynolds number, and (b) Nu vs. Re 


\section{RESULTS AND DISCUSSION}

In the present study, a particle size of $20 \mathrm{~nm}$ was used as the working fluid at three different concentrations $(0.5 \%, 1 \%$, and $1.5 \%)$. The values of Re are in the ranged from 6300 to 27500 , and for $\mathrm{Nu}$ are from 48 to 130 , as shown in Figure 5, for the boundary conditions used in this simulation study, the steady-state pressure was considered for all calculations. The standard SST and k- $\varepsilon$ turbulence model with realizable are considered with the second-order upwind scheme. The SIMPLE scheme for the pressure - velocity coupling is implemented.

The developed model was analyzed with flow path modification along the spirally grooved tube with a twisted tape (TT) inserted. Two different twisted ratios were selected for the study, which called (2 and 5). The influence of nanoparticle in the base fluid on heat transfer is shown in Figure8. The Nusselt number is inversely proportional to TT. The variation of the Nusselt number for various twist ratios at the corresponding Reynolds numbers is shown in Figure 5a. It can be seen that the Nusselt number increased with the nanoparticle concentration. It was found that the thermo-physical of the nanofluid contributed to a larger extent in improving the rate of heat transfer by adding nanoparticles to the base fluid. The combined effect of twisted tape with $0.5 \%, 1 \%$, and $1.5 \%$ and the concentration of A12O3-EG nanofluid is shown in Figure 4b. It was found that there was a significant improvement in the Reynolds's number and increments in the Nusselt number under twisted tapes and nanofluid flowing through the test section. For $6300<\mathrm{Re}<27500, \mathrm{Nu}$ is $90<\mathrm{Nu}<360$ with an average increment of $38.46 \%$. The literature revealed that the swirl flow generated in the occurrence of twisted tape that enhances the heat transfer coefficient. It is further reported that with a decrease in the twisted ratio, the wall shear resistance was found to be higher at the wall with a maximum dissipation of energy. This leads to a lower inflow of the local velocities. The Nusselt number was found to be higher for a twisted ratio of 2 with a $0.5 \%$ volume concentration of nanofluid and lower for the twisted tape with $\mathrm{TR}=5$. The average enhancement of the Nusselt number for TR $=2$ with $\varphi=1.5 \%$, is found to be $42.81 \%$ compared to the base fluid. The friction factor varies with the change in the volume concentration of the nanofluid and with the inserts of twisted tape (TT) of various twisted ratios (TR). The effect of TR and $\varphi$ on the friction factor is shown in Figure $5 b$.
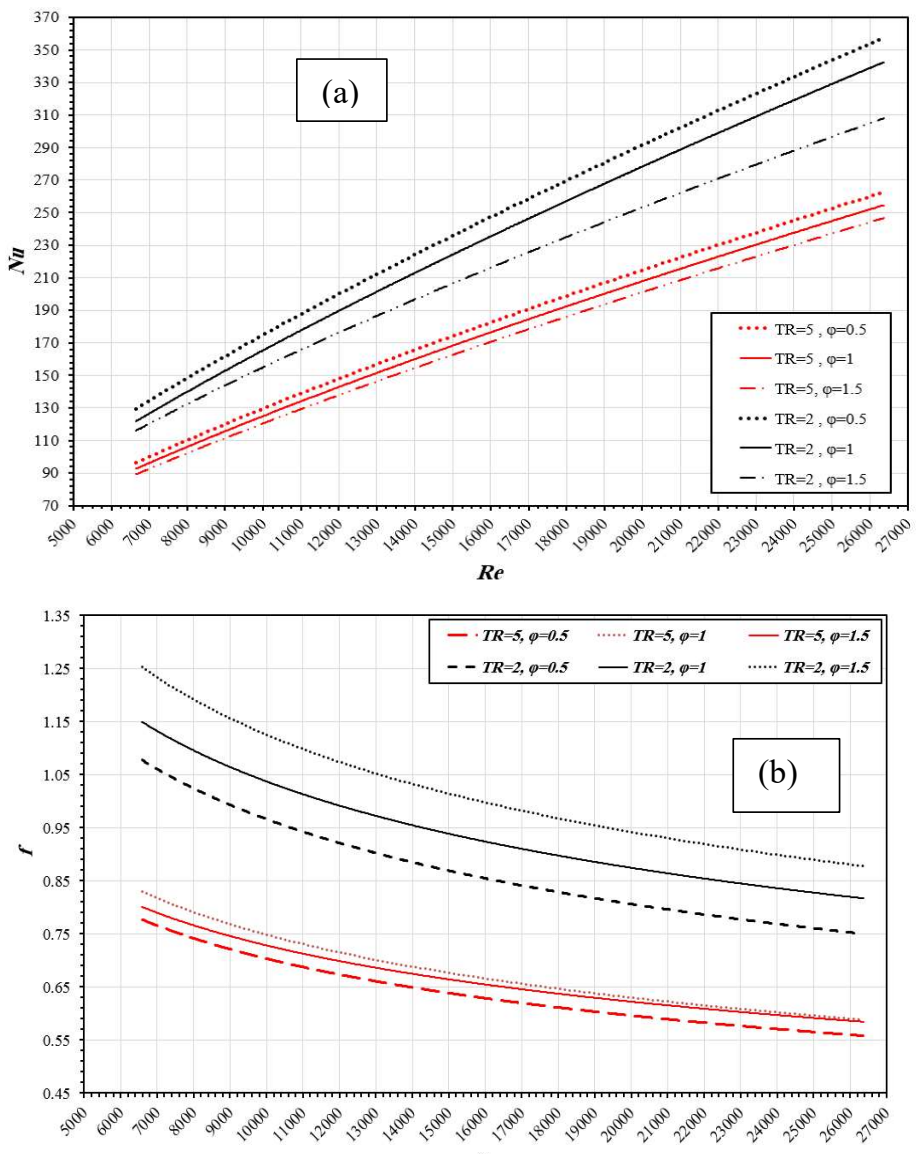

Figure 5. Effect of $\mathrm{I} K$ and concentration on, (a) Nusselt number, and (b) Friction factor 
The friction factor increases with a decrease in the TR for $6300<\operatorname{Re}<27000$, as observed in Figure 6 . The friction factor was increased by 40 times for water flow in the internal plain tube. The friction factor was 49 times the value of the base fluid in a plain tube for $\mathrm{TR}=5, \varphi=0.5 \%, \mathrm{Re}=6300$. The values of the friction factor for various $\mathrm{TR}$ and different Reynolds numbers at $\varphi=0.5 \%, 1 \%$, and $1.5 \%$ are shown in Figure $5 \mathrm{~b}$. The heating pipe efficiency ( $\eta$ ) was calculated based on the following relation:

$$
\eta=\frac{h_{E}}{h_{N E}}
$$

Which is represented as the ratio between heat transfer by convection enhancement $h_{E}$, and the non-enhanced one $h_{N E}$, for the same power delivered. The behavior of this efficiency with variation Reynolds number is presented in Figure 6. It is clear from Figure 6 that $(\eta)$ decreases with Re, and also it can be noted that the twisted ratio (TR) for tape is decreased. Furthermore, the efficiency of the heating pipe is increased for the same Reynolds number value by $40 \%$, which is proved by the temperature contour, as shown in Figure7. For the same twisted ratio, the performance was inversely proportional to the concentration. It can be concluded that the best thermal performance can be reached at a small twisted ratio and concentration values.

The friction factor for the same TR is comparable with the nanofluid volume fraction by viscosity, the friction factor is inversely proportional to TR, the temperature of the outlet mixer increases as the volume of the fraction increases and the air outlet temperature increases for the same VOF as the TR.

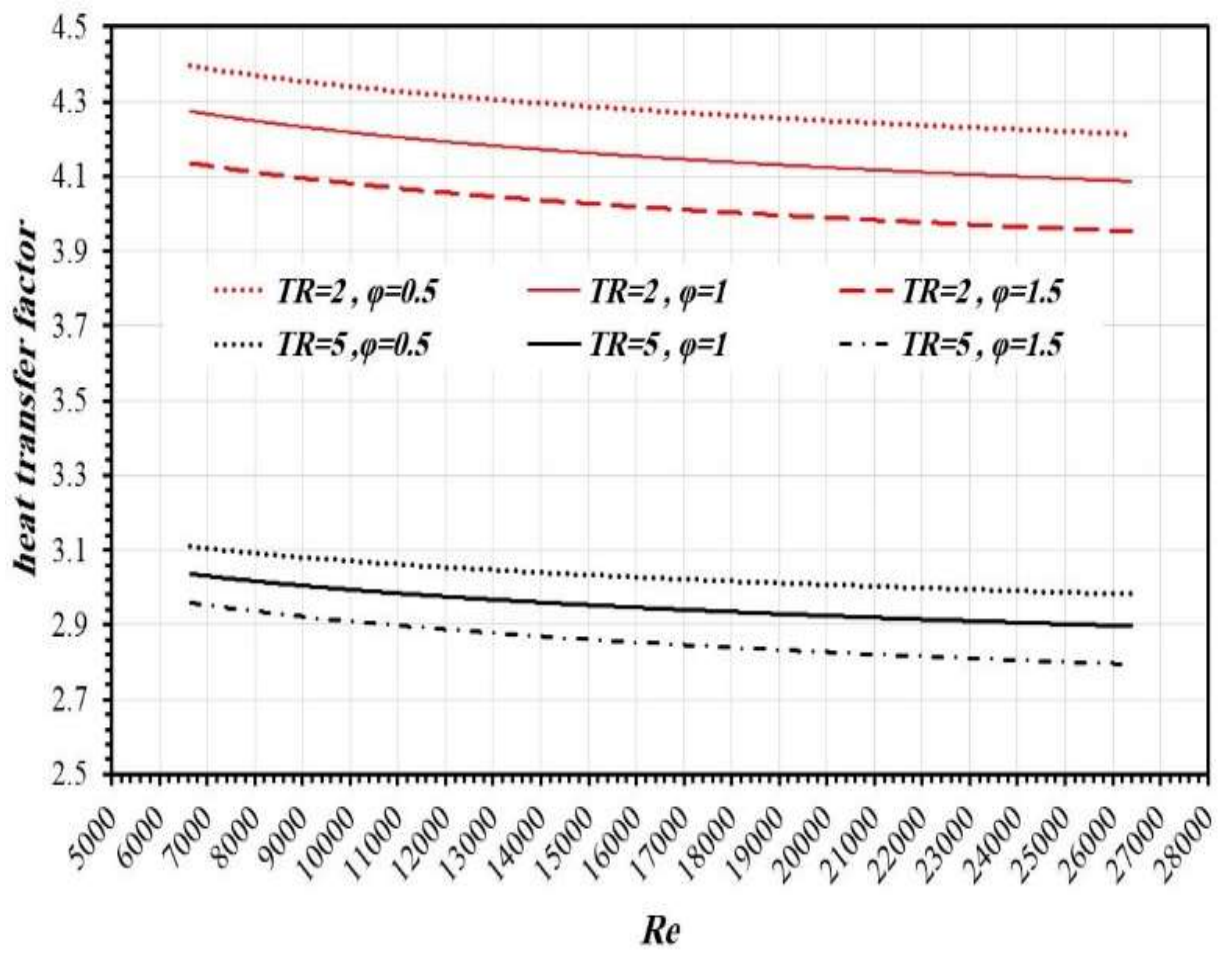

Figure 6. Effect of TR and concentration on the heat transfer 


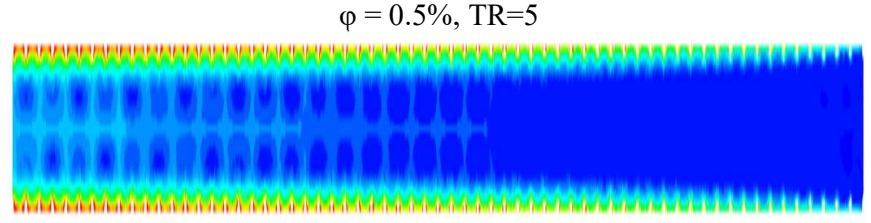

$\varphi=1 \%, \mathrm{TR}=5$

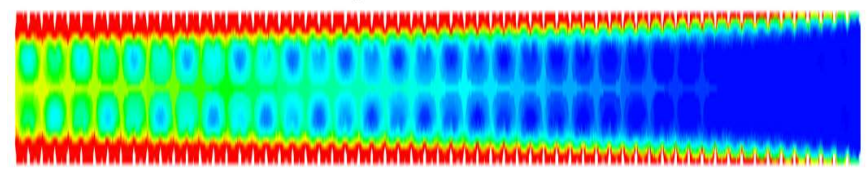

$\varphi=1.5 \%, \mathrm{TR}=5$

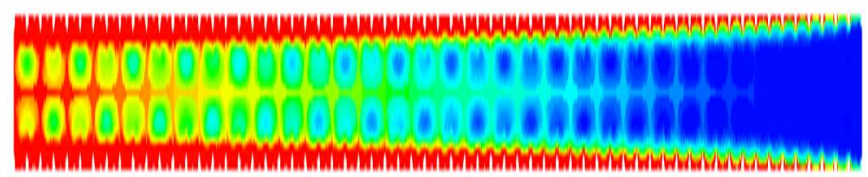

$\varphi=0.5 \%, \mathrm{TR}=2$

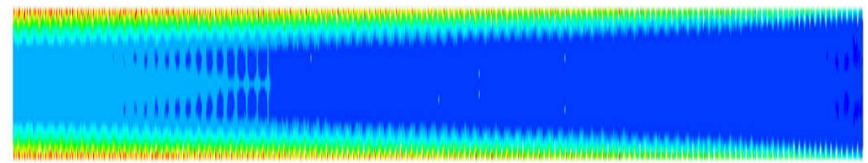

$\varphi=1 \%, \mathrm{TR}=2$

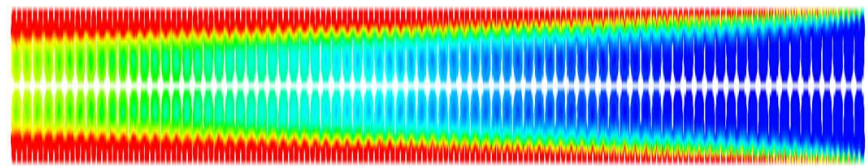

$\varphi=1.5 \%, \mathrm{TR}=2$

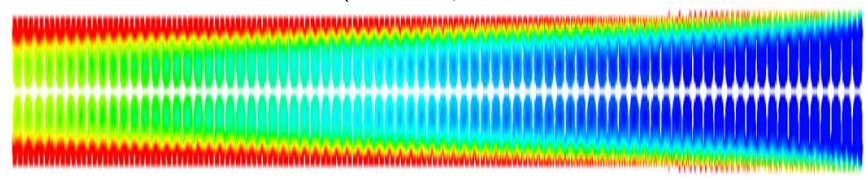

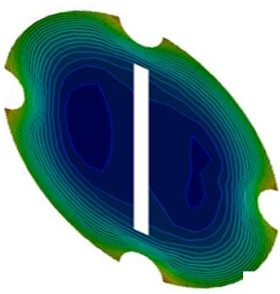

$\varphi=0.5 \%, \mathrm{TR}=5$ Tout $=377.482[\mathrm{~K}]$
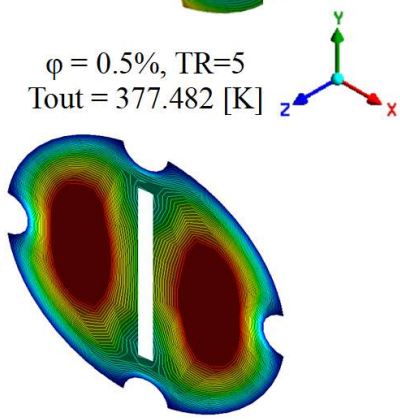

$\varphi=1 \%, \mathrm{TR}=5$

Tout $=545.111[\mathrm{~K}]$
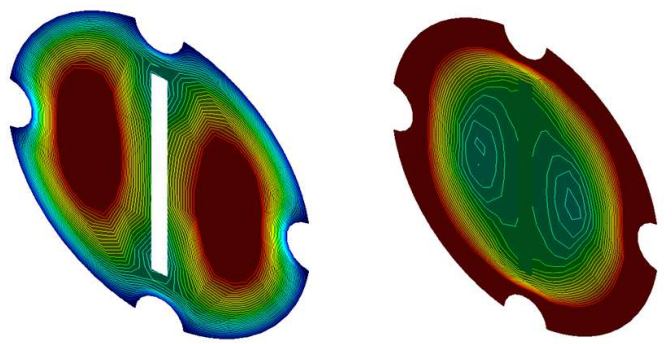

$\varphi=1.5 \%, \mathrm{TR}=5$

Tout $=629.07[\mathrm{~K}]$ $\varphi=0.5 \%, \mathrm{TR}=2$

Tout $=543.464[\mathrm{~K}]$

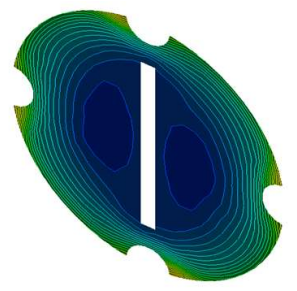
Tout $=374.487[\mathrm{~K}]$

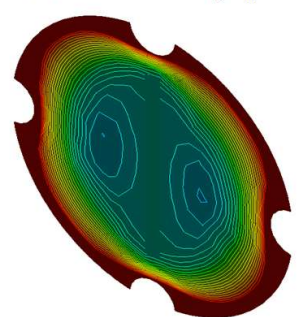$$
\varphi=1 \%, \mathrm{TR}=2
$$

$\varphi=1.5 \%, \mathrm{TR}=2$ Tout $=623.912[\mathrm{~K}]$

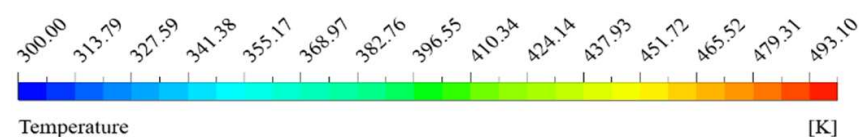

(a) Temperature distribution in YZ-plane with flow direction (Z-axis)

(b) Temperature distribution in XY-plane at $\mathrm{Z}=0.6 \mathrm{~m}$.

Figure 7. Temperature contours

\section{Flow Pattern with Twisted Tape}

The heat transfer increased when twisted tape and corrugated tubes were used. This is happened because of the swirl flow. The swirl flow is dominant, as shown in Figure8. This led to an increase in the heat transfer for a corrugated tube with TT more than that for the corrugated tube only. Figure8 and Fig9 explain the secondary stream and pressure drop in the mixed-flow production. As a result of good mixing occurred in the twisted tape and spirally corrugated tube, the heat transfer increased. In addition, that a clear decrease in pressure drop along the tube in the direction of the flow has happened. Therefore, the coefficient of friction increases due to the increase in the contact surface area between the solid and fluid parts. 

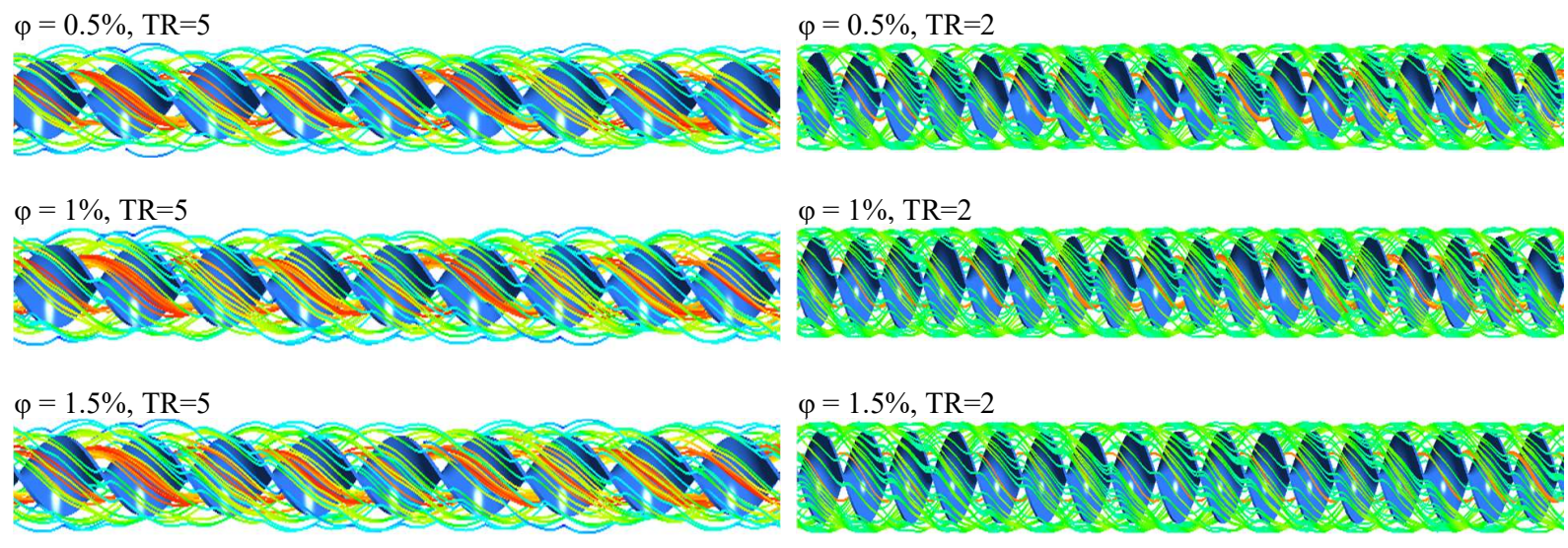

$\varphi=1.5 \%, \mathrm{TR}=2$

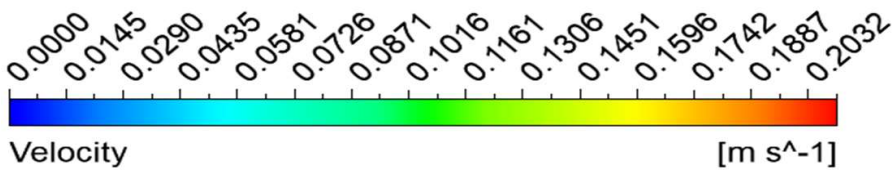

Figure 8. Effect of twisted tape on flow streamline

$\varphi=0.5 \%, \mathrm{TR}=5$

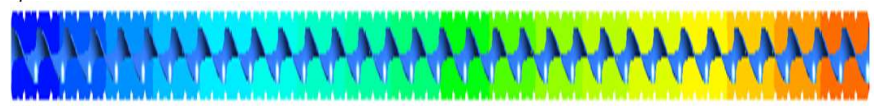

$\varphi=1 \%, \mathrm{TR}=5$

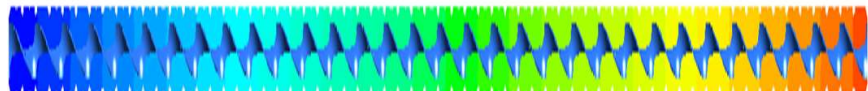

$\varphi=1.5 \%, \mathrm{TR}=5$

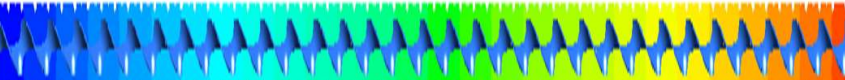

$$
(n=0.5 \% . \mathrm{TR}=2
$$

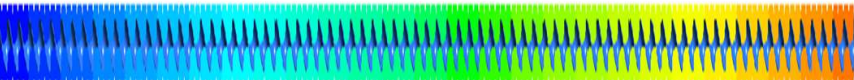

$\varphi=1 \%, \mathrm{TR}=2$

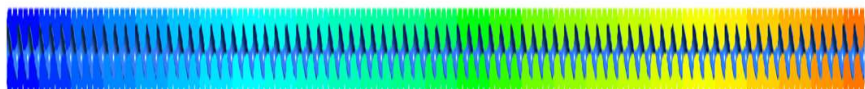

$\varphi=1.5 \%, \mathrm{TR}=2$

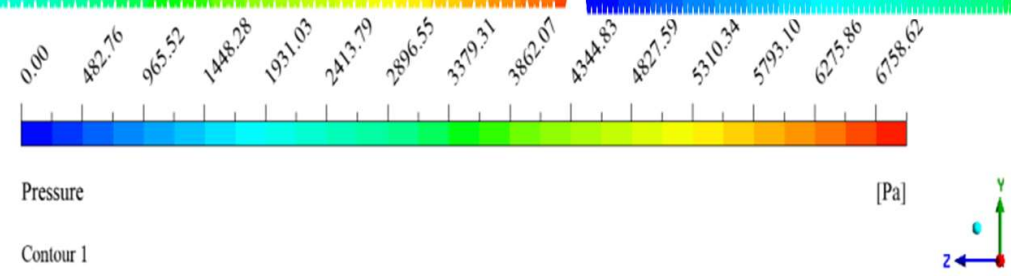

Figure 9. Pressure drops on flow pattern with corrugated tube and a twisted tape inserted

\section{CONCLUSION}

This paper numerically investigates the effects of the twist ratio (TR) and fraction volume in nanofluids on thermal performance and the friction factor properties. This is done for turbulent flow via a spiral tube which is fitted with twisted tape. From this numerical study, the following conclusions can be drawn, the heat transfer for A12O3/ (EG-water) nano-fluid is improved compared to water or Al2O3-water, Heat transfer increased with decreasing TR. The friction factor for the same TR is comparable with the nanofluid volume fraction by viscosity, the friction factor is inversely proportional to TR, the temperature of the outlet mixer increases as the volume of the fraction increases and the air outlet temperature increases for the same VOF as the TR. 


\section{NOMENCLATURE}

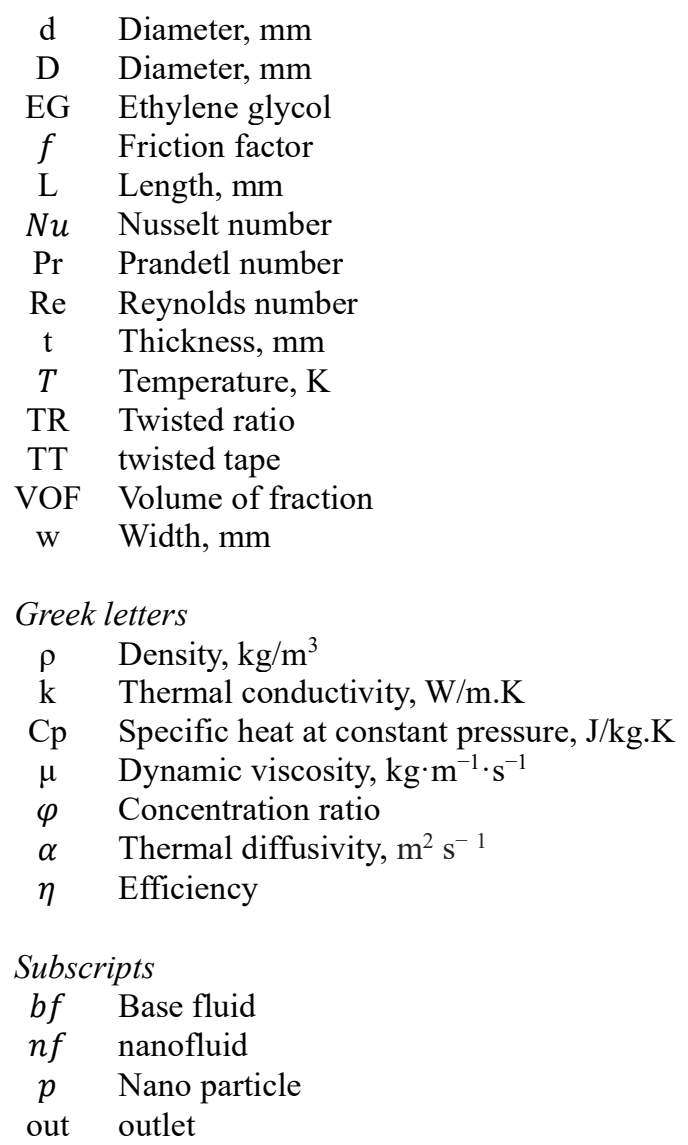

\section{REFERENCES}

[1] Mohammadiun H, Mohammadiun M, Hazbehian M, Maddah H. Experimental study of ethylene glycol-based Al 2 O 3 nanofluid turbulent heat transfer enhancement in the corrugated tube with twisted tapes. Heat Mass Transf 2016;52:141-51.

[2] Qi C, Wan Y-L, Li C-Y, Han D-T, Rao Z-H. Experimental and numerical research on the flow and heat transfer characteristics of TiO2-water nanofluids in a corrugated tube. Int J Heat Mass Transf 2017;115:1072-84.

[3] Hashim WM, Hoshi HA, Al-Salihi HA. Enhancement the performance of swirl heat exchanger by using vortices and NanoAluminume. Heliyon 2019;5:e02268.

[4] Jayakumar JS, Mahajani SM, Mandal JC, Iyer KN, Vijayan PK. CFD analysis of single-phase flows inside helically coiled tubes. Comput Chem Eng 2010;34:430-46.

[5] Thianpong C, Eiamsa-Ard P, Promvonge P, Eiamsa-Ard S. Effect of perforated twisted-tapes with parallel wings on heat tansfer enhancement in a heat exchanger tube. Energy Procedia 2012;14:1117-23.

[6] Nadila NI, Lazim TM, Mat S. Verification of heat transfer enhancement in tube with spiral corrugation. AIP Conf. Proc., vol. 2062, AIP Publishing LLC; 2019, p. 20032.

[7] Abu-Mulaweh HI. Experimental comparison of heat transfer enhancement methods in heat exchangers. Int J Mech Eng Educ 2003;31:160-7.

[8] Shrirao PN, Sambhe RU, Bodade PR. Experimental Investigation on Turbulent Flow Heat Transfer Enhancement in a Horizontal Circular Pipe using internal threads of varying depth. IOSR J Mech Civ Eng 2013;5:23-8.

[9] Song D, Hatami M, Wang Y, Jing D, Yang Y. Prediction of hydrodynamic and optical properties of TiO2/water suspension considering particle size distribution. Int J Heat Mass Transf 2016;92:864-76.

[10] Piriyarungrod N, Eiamsa-Ard S, Thianpong C, Pimsarn M, Nanan K. Heat transfer enhancement by tapered 
Journal of Thermal Engineering, Technical Note, Vol. 7, No. 4, pp. 761-772, May, 2021

twisted tape inserts. Chem Eng Process Process Intensif 2015;96:62-71.

[11] Promthaisong P, Jedsadaratanachai W, Eiamsa-Ard S. Effect of geometrical parameters on turbulent flow and heat transfer behaviors in triple-start corrugated tubes. J Therm Sci Technol 2018;13:JTST0008-JTST0008.

[12] Li Y, Wu J, Wang H, Kou L, Tian X. Fluid flow and heat transfer characteristics in helical tubes cooperating with spiral corrugation. Energy Procedia 2012;17:791-800. 